\title{
Mobilisation of satellite cells following ischaemia and reperfusion in primate skeletal muscle
}

\author{
M A Gregory (PhD) ${ }^{1}$ \\ M Mars (MB ChB, MD) $)^{2}$ \\ 'Electron Microscope Unit, University of KwaZulu-Natal, Durban \\ ${ }^{2}$ Department of TeleHealth, Nelson R Mandela School of Medicine, University of KwaZulu-Natal, Durban
}

\begin{abstract}
Objective. To describe the morphological and morphometric features of activated skeletal muscle satellite cells in primates, using an ischaemic reperfusion model.

Setting. The study was undertaken at the Biomedical Resource Centre and the Electron Microscopy Unit of the University of KwaZulu-Natal.

Interventions. Eight vervet monkeys were anaesthetised and subjected to 3 hours of tourniquet-induced lower limb ischaemia. Open muscle biopsies were taken from tibialis anterior muscle immediately after tourniquet release and $12,24,36$ and 48 hours after tourniquet release. Control biopsies were taken from the opposite limb.

Main outcome measures. Description of the morpholog ical and morphometric changes in satellite cells after activation, as seen on transmission electron microscopy.

Results. Two distinct patterns of satellite cell activation are described. In group 1, the cytoplasm of the satellite cell expands around the myocyte and the gap between the satellite cell and the myocyte appears to break down, or in group 2, the novel observation of the satellite cell breaking away from the myofibre and becoming a myocyte totally encased in its own basal lamina. The satellite cells of group 1 were significantly longer than the group 2 cells $(p=0.018)$ and this was associated with a significant reduction in the percentage of nuclear to cell area $(p=0.011)$.

Conclusions. Tourniquet-induced ischaemic reperfusion injury is shown to result in two distinct patterns of satellite cell activation which may represent different functions or subsets of satellite cells.
\end{abstract}

\section{CORRESPONDENCE:}

\section{Mars}

Department of TeleHealth

Nelson R Mandela Medical School

Private Bag X7

Congella 4013

KwaZulu-Natal

Tel: 031-260 4364

Fax: 031-260 4455

E-mail:mars@nu.ac.za

\section{Introduction}

Satellite cells were first described by Mauro in 1961. ${ }^{30}$ They form a distinct and separate population of undifferentiated, myogenic cells within all vertebrate skeletal muscle. These small cells, with a large nuclear to cytoplasmic ratio, are found sandwiched between the basal lamina and sarcolemma of each myofibre. They are distinct from the myonuclei of the multinucleate skeletal muscle fibre, which lie under both the basal lamina and the sarcolemma and which lose the capacity to undergo mitosis soon after birth. Satellite cells are now known to be the cells involved in muscle development and growth, ${ }^{21}$ repair $^{43}$ and regeneration after muscle injury ${ }^{19,22}$ and are implicated in the changes in muscle ageing. ${ }^{14}$

The number and distribution of satellite cells in a muscle are dependent on the species, age and muscle fibre type and in primates they comprise from $1 \%$ to $3 \%$ of the nuclei in adult skeletal muscle. ${ }^{14,42}$ They are not uniformly distributed throughout muscle and are more commonly found near capillaries, neuromuscular junctions and myonuclei. ${ }^{7,38,50}$

During normal muscle growth, quiescent satellite cells are reported to proliferate and fuse with their host myofibre. ${ }^{41,42}$ They may also be activated by exercise and muscle injury, causing a sequence of morphological transformations that is less well documented..$^{38}$ Repeated resistance training results in hypertrophy and is also associated with myofibre microtrauma that necessitates repair. In resistance exercise- induced hypertrophy, repeated microtrauma leads to macrophage regulated cytokine activation of satellite cells. This results in the production and replacement of nuclear material and satellite cell proliferation, with migration by chemotaxis and fusion to existing fibres. ${ }^{5,36,39,41,42}$ Mobilisation of satellite cells following microtrauma is reported as being of two forms - sub-basal laminar migration to the damaged area if the integrity of the basal laminar is not disturbed, and migration to adjacent myofibres using tissue bridges if the basal lamina is disrupted. ${ }^{41,42,48}$

Most reports describe the morphology of satellite cells in their quiescent state and as a uniform cell line.$^{32}$ While it is generally held that satellite cells evolve from the multi-potential mesodermal cells of the embryonic somite, ${ }^{34,42}$ there is evidence to suggest that satellite cells may also be derived from endothelial cells or a common precursor. This and differential gene expression in quiescent satellite cells suggests that there may be more than one satellite cell line. These cell lines respond differently to activation and on any muscle fibre, some function as stem cells and others are available for fusion. ${ }^{42} \mathrm{~A}$ new population of adult skeletal muscle-derived, pluripotential stem cells called side population cells have recently been identified using a fluorescent dye exclusion, flowcytometric method. 
These cells are a subpopulation of the satellite cell pool. In vitro cultures of side population cells have the ability to reconstitute lethally damaged bone marrow in vivo. In regenerating muscle, the number of myogenic precursors exceeds that of resident satellite cells and this implies migration or recruitment of undifferentiated progenitors from other sources. ${ }^{11,15,16,34,42}$ Supporting this, cultured bone marrow cells have been shown to be able to differentiate into myoblasts under the appropriate stimuli. ${ }^{6,16}$

The role of satellite cells in the effects of ageing on skeletal muscle is also an area of growing recent interest. ${ }^{23}$ Satellite cells in people over the age of 60 years have been shown to proliferate normally but to produce thinner and more fragile myotubes. Theoretically every cell has the capacity to divide a finite number of times, in the region of 60 - 70 divisions. Each division results in shortening of the telomeres, or ends of the chromosomes, and ultimately the telomeres reach a critical length, at which point the cell can no longer divide. ${ }^{22}$ Of interest is whether years of training and associated satellite cell activation will lead to a premature reduction in the total number of satellite cells due to loss of the ability of satellite cells to divide and hasten muscle ageing.

Satellite cells also play a role in myopathies. In Duchenne's muscular dystrophy, the myofibres are deficient in the cytoskeletal protein dystrophin. This renders them fragile and normal muscle contractions can lead to muscle damage and degeneration. This leads to satellite cell activation and the production of new myofibres that are also dystrophin deficient. Eventually the satellite cell pool is depleted. In the $m d x$ mouse model which lacks dystrophin, myoblasts (satellite cells) cultured in vitro have been successfully injected into pathological muscle to supplement defective satellite cells. ${ }^{6,25,28}$ This opens the possibility of supplementing satellite cell populations to both augment hypertrophy and to delay muscle ageing.

Skeletal muscle blood flow is not homogeneous throughout a contracting muscle. During both dynamic and isometric muscle contractions blood supply within the working muscle varies and localised areas of relative ischaemia may occur. There are no reports of the effect of ischaemic reperfusion injury on satellite cell activation. The existing models of muscle regeneration and satellite cell activation include gene knockout, muscle crush injury, chemically induced muscle injury and freezing injury. The aim of this study was to investigate the morphological changes in satellite cells using tourniquet-mediated ischaemic/reperfusion injury as a model.

\section{Animals and methods}

Eight adult vervet monkeys were studied. They were cared for according to the requirements of the National Code for the Use of Animals in Research and the study was undertaken with the approval of the Ethics Committees of the University of Natal and the University of Durban-Westville. Anaesthesia was induced with ketamine $(15 \mathrm{mg} / \mathrm{kg}$ ) by intramuscular injection and maintained with sodium thiopentone $(25 \mathrm{mg} / \mathrm{kg})$ intravenously, as necessary. The animals' temperature and blood pressure were monitored during anaesthesia. They were awakened after tourniquet release. Subsequent muscle biopsies were performed after intramuscular administration of ketamine (15 mg/kg).

A hind limb was exsanguinated using an Esmarch bandage and a pneumatic tourniquet applied to the thigh at $100 \mathrm{mmHg}$ above systolic pressure. The tourniquet was maintained for 3 hours. In 4 animals, open muscle biopsies were taken from the tibialis anterior muscle before tourniquet application and 6 hours, 24 hours and 48 hours after tourniquet release. In the remaining 4 animals, biopsies were taken before tourniquet application, and 12 hours and 36 hours after tourniquet deflation. The skin was sutured with $3 / 0$ nylon after each biopsy.

\section{Electron microscopy}

In order to exclude super-contraction artefact in myofibres, the tissue was desensitised to further mechanical trauma by immediate immersion in $0.1 \mathrm{M}$ cacodylate buffered Karnovsky's fixative $^{24}$ for 10 minutes. After desensitisation, the central artefact-free core of the biopsy specimen was removed as described by Olmesdahl et al. ${ }^{33}$ and diced into $1 \mathrm{~mm}$ cubes before re-immersion in fixative for a further 1 hour. After postfixation/staining with $1 \%$ osmium tetroxide, the tissue was dehydrated through increasing concentrations of ethanol before being embedded in Spurr epoxy resin. ${ }^{46}$ Four $1 \mathrm{~mm}^{3}$ blocks of tissue were prepared from each specimen.

Sections, $1 \mu \mathrm{m}$ thick, were cut off each block, stained with $1 \%$ alkaline toluidine blue and examined by light microscopy. Using the $1 \mu \mathrm{m}$ sections as indicators, the blocks were orientated so that myofibres could be cut in longitudinal section. Ultrathin sections of approximately $60 \mathrm{~nm}$ were cut from each block using a diamond knife. To increase the surface area for examination and thereby improve the probability of satellite cell detection, ultrathin sections were obtained from five deeper levels $(100 \mu \mathrm{m})$. Ultrathin sections were mounted on copper grids and stained with $1 \%$ ethanolic uranyl acetate and Reynolds lead citrate ${ }^{35}$ prior to examination with a Jeol 1010 transmission electron microscope (TEM).

\section{Morphometry}

Images of whole satellite cells were captured using a Kodak Megaplus slow-scan video camera and measurements made using an analySIS 2.1, image analytical system. Quiescent satellite cells in normal, untraumatised muscle have been reported to take up a position oblique to the long axis of the myofibre. ${ }^{1}$ As all bundles of myofibres had, as far as possible, been cut in longitudinal section, most satellite cells should have been cut in transverse transverse/oblique section. Satellite cell length and width were measured, and satellite cell circularity, cell volume and nuclear volume were calculated.

Statistical analysis was by unpaired $t$-test with Welch's correction when Bartlett's test had shown a significant difference between standard deviations. Analysis of variance was by the non-parametric Kruskal-Wallis test with Dunn's multiple comparison test used for post hoc testing.

\section{Results}

A careful light microscopic examination of the $1 \mu \mathrm{m}$ sections was unable to unequivocally locate or identify satellite cells as independent entities in any specimen. Satellite cells, therefore, were only identified by carefully examining ultrathin sections using the TEM. Even though five levels had been cut from each block, small block size and thinness of section, together with the normally sparse number of satellite cells in muscle tissue 
resulted in very few 'whole', nucleated satellite cells being found in each specimen. While non-nucleated portions of satellite cells were found beneath the basal lamina of fibres in many sections, only 25 intact, nucleated satellite cells/myoblasts were found.

In the absence of a classification system for satellite cells in various stages of activation, we have used their morphological features and morphometry to classify activated satellite cells/myoblasts into two groups. Group 1 describes those cells in which the plasmalemma remained close to the sarcolemma of their host myofibre and which underwent marked changes in the ratio of nuclear to cell length. Based on their shape and size, group 1 satellite cells were further subdivided into the following phases of activation: quiescent, early activation, and fully mobilised. Group 2 describes cells that appeared to be separating from their host myocyte and were classed as being either in various phases of separation from their host myocyte or fully motile, interfibre myoblasts.

Group 1: Quiescent satellite cells $(\boldsymbol{N}=4)$, were present in control samples and in some specimens up to 12 hours after reperfusion. They averaged $6.5 \mu \mathrm{m}$ in length, $2.9 \mu \mathrm{m}$ in width and were generally oval in shape (circularity 0.47 ). They contained a large rounded/oval nucleus which occupied approximately $60 \%$ of the total transversely sectioned area of each cell (Fig. 1). The plasmalemmae of quiescent satellite cells (SC) were separated from the sarcolemma of their host myocyte by a gap approximately 25 - $30 \mathrm{~nm}$ in width (Fig. 2). No desmosomes joined the cells and no electron-dense material was present in the intercellular gap. The cytosol contained small mitochondria with distinct cristae, occasional Golgi cisternae, $\alpha$-glycogen particles, free ribosomes and strands of endoplasmic reticulum. Chromatin, while dispersed throughout each nucleus, was especially aggregated beneath the nucleolemma.

Group 1: Early activated satellite cells $(N=6)$ were found in specimens from 6 to 24 hours after reperfusion. The early phases of activation were characterised by either an elongation or reorientation (to the long axis of the fibre) of satellite cells (circularity 0.29 ). Cells in this category ranged from $10 \mu \mathrm{m}$ to $15 \mu \mathrm{m}$ in length and averaged $3.4 \mu \mathrm{m}$ in depth. While the average cross-sectional area of early mobilised (EM) satellite cells had nearly doubled from $14.4 \mu \mathrm{m}^{2}$ to $27.1 \mu \mathrm{m}^{2}, 2,20$ the proportion occupied by the nucleus was only marginally reduced from $60 \%$ to $55 \%$. The plasmalemmae of the two cells remained approximately $30 \mathrm{~nm}$ apart. While satellite cell mitosis was not visualised, 2 of the 6 cells in this group contained centrioles (Fig. 3). Cytoplasmic organelles were morphologically similar to those quiescent cells. There was perhaps a little more clumping of chromatin in these cells.

Group 1: Fully mobilised satellite cells $(N=7)$ were present in muscle from 12 to 48 hours after reperfusion. These cells ranged in length from $23 \mu \mathrm{m}$ (Fig. 4) to $60 \mu \mathrm{m}$ in length (Fig. 5) and averaged $2.8 \mu \mathrm{m}$ in width (circularity 0.11 ). Again, while the average cross-sectional area had nearly doubled from $27 \mu \mathrm{m}^{2}$ to $51 \mu \mathrm{m}^{2}$, the proportion occupied by the nucleus was only reduced by $5 \%-50 \%$. In most cases, the cell plasmalemmae were separated by a gap of approximately $30 \mathrm{~nm}$ (Fig. 6). In some instances, however, adjacent regions of satellite cell plasmalemma and sarcolemma appeared to have broken down with the cytosol-sarcosol of the two cells merging (Fig. 7). Fragments of the 2 plasmalemmae were still visible in

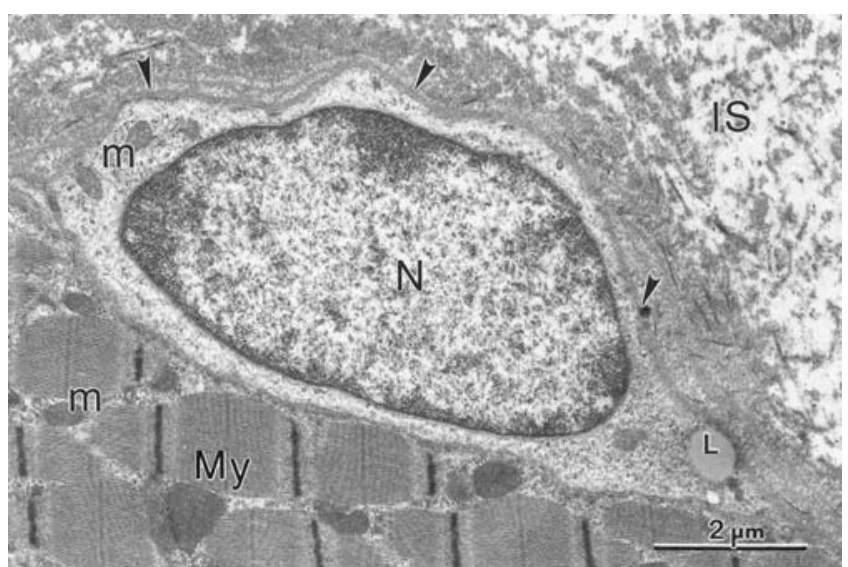

Fig. 1. Group 1 quiescent: Transmission electron micrograph of a typical quiescent satellite cell from a control muscle biopsy. Note the large, oval nucleus (N), sparse small mitochondria (m) and occasional lipid droplets (L) (My = skeletal myosite and arrow heads point at the basal lamina over the satellite cell surface).

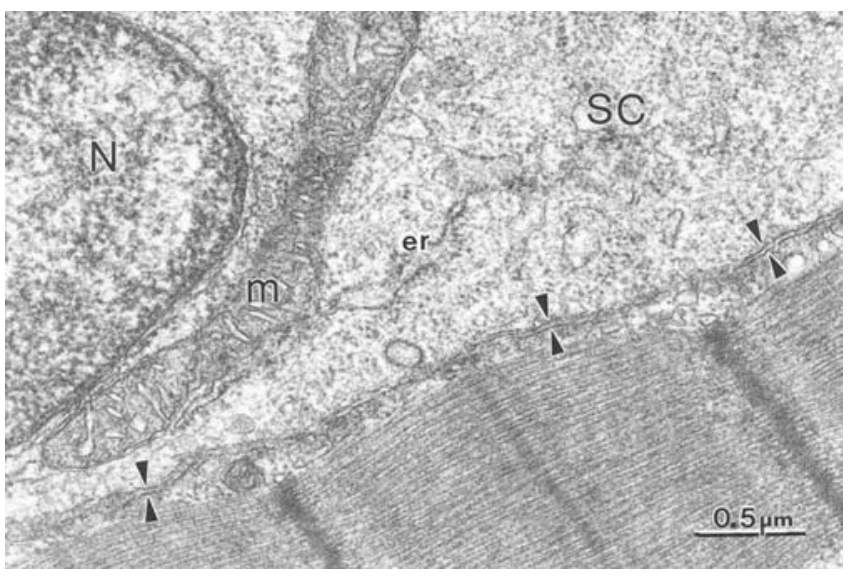

Fig. 2. Group 1 Quiescent: Transmission electron micrograph showing the detail of the separation between satellite cell (SC) plasmalemma and the myocyte sarcolemma (arrow-heads) in control muscle (Er = endoplasmic reticulum of the satellite cell).

places. Centrioles were not present in extensively elongated cells. However, even in peripheral regions, the cytoplasm contained numerous mitochondria, well-developed Golgi apparatus, numerous $\alpha$-glycogen particles and free ribosomes, all features suggestive of high metabolic activity.

Group 2: These separating satellite cells $(N=6)$ were present in muscle from 6 to 24 hours after reperfusion. Like quiescent cells, they tended to be oval and ranged in length from $5.1 \mu \mathrm{m}$ to $9.5 \mu \mathrm{m}$ and averaged $2.9 \mu \mathrm{m}$ in width (circularity 0.38). The mean cross-sectional area of the separating cells was approximately $30 \%$ greater than that of the quiescent cells $\left(19.3 \mu \mathrm{m}^{2}\right)$ and the average area occupied by nuclei was $6 \%$ greater $(66 \%)$. While still contained within the basal lamina of host myofibres, separating satellite cells were all characterised by the presence of basal lamina between the satellite cell plasmalemma and fibre sarcolemma. Fig. 8 shows what appears to be an 'in-growth' of the basal-lamina between a satellite cell and fibre with the satellite cell being separated from its host by a gap of $270 \mathrm{~nm}$. In addition to all cells being separated from 


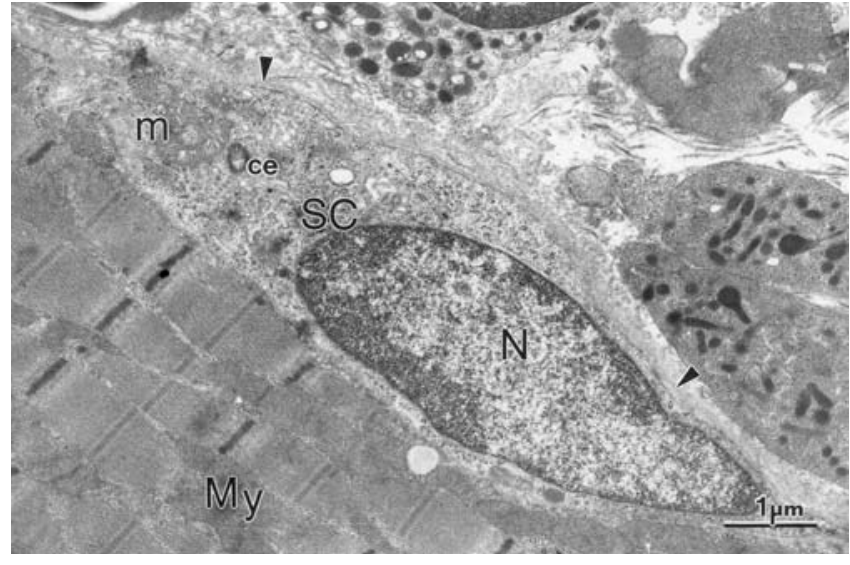

Fig. 3. Group 1. Early activation, after 12 hours of reperfusion. Transmission electron micrograph showing elongating satellite cell. Note the increase in mitochondria and cytoplasmic vesicles ( $\mathrm{Ce}=$ centriole; arrow heads show the basal lamina).

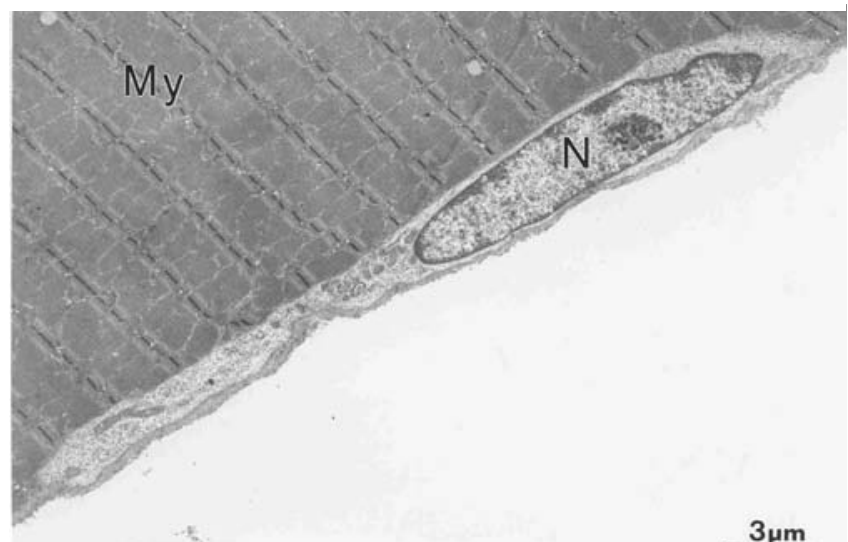

$\underline{3} \mu \underline{m}$

Fig. 4. Group 1. Mobilised, after 24 hours of reperfusion. Transmission electron micrograph showing an elongated satellite cell ( $N=$ nucleus, $M y=$ skeletal myocyte).

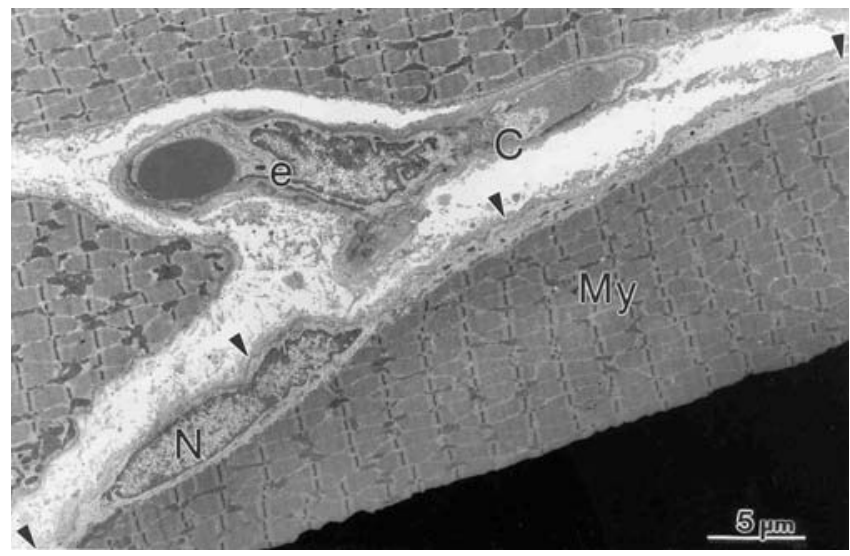

Fig. 5. Group 1 mobilised, after 36 hours of reperfusion. Transmission electron micrograph showing a very elongated satellite cell. The arrow heads show the extent of the cell (C = capillary, e = endothelial cell).

their hosts, all separating satellite cells differed from quiescent cells in that they contained large irregularly shaped, bi-lobed nuclei containing aggregates of chromatin. While probably only

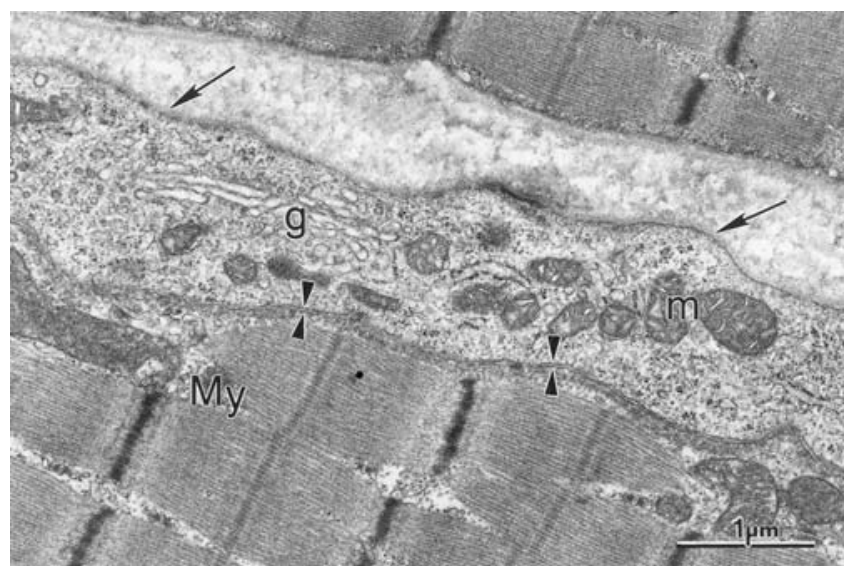

Fig. 6. Group 1 mobilised, after 36 hours of reperfusion. Transmission electron micrograph showing detail of separation between satellite cells plasmalemma and the skeletal (My) myocyte sarcolemma (arrowheads). ( $G$ = Golgi apparatus, $m=$ mitochondria and arrows show the basal lamina.)

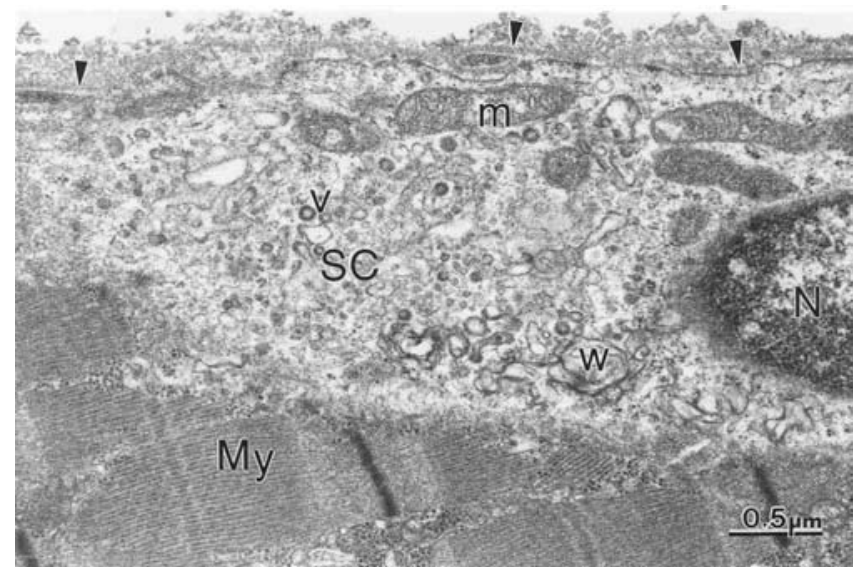

Fig. 7. Group 1 mobilised, after 36 hours of reperfusion. Transmission electron micrograph showing detail of the apparent fusion between the satellite cell (SC) and the skeletal myocyte (My). Note the absence of sarcolemmal plasmalemma, numerous coated vesicles and occasional whorls of membranous material (w).

a consequence of the plane of sectioning, the lobular shape of the nucleus in one satellite cell suggested that the cell had two nuclei (Fig. 9). Other cytoplasmic organelles were similar to those in quiescent cells. Although retaining focal attachments to their host myofibre, separating satellite cells were characterised by extensive intercellular gaps often filled with whorls of membranous material (Figs 9 and 10). In one instance, while still nestled within an indentation of a myofibre, a separating satellite cell was entirely encapsulated by basal lamina (Fig. 11). This cell containing a clearly defined centriole had an irregularly shaped, bi-lobed nucleus with aggregates of chromatin at each pole.

Group 2: Intercellular myoblasts $(\boldsymbol{N}=2)$ were present in the specimens from 36 to 48 hours after reperfusion. They averaged $11.6 \mu \mathrm{m}$ in length and $4.5 \mu \mathrm{m}$ in width, with a circularity of 0.37 . The mean cross-sectional area of the myoblasts was $37 \mu \mathrm{m}^{2}$ and the average area occupied by nuclei was $54 \%$ (Table I). These cells were encapsulated by a well defined 


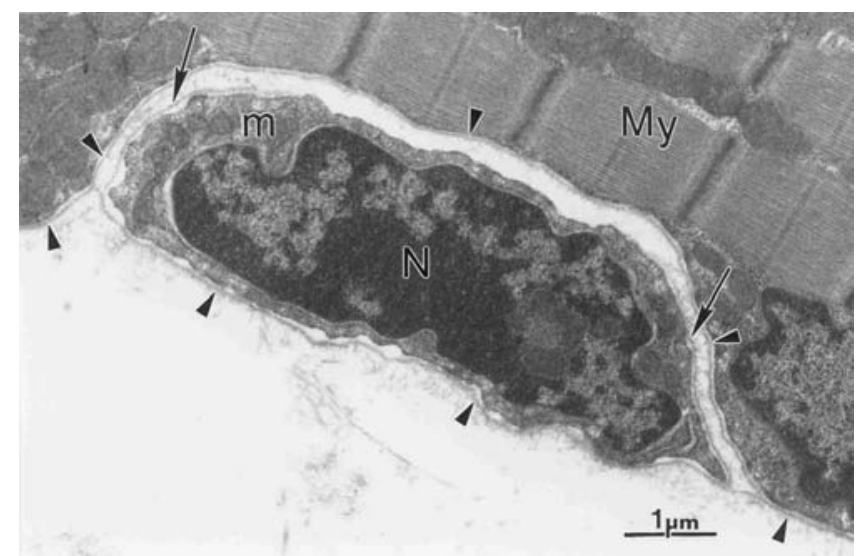

Fig. 8. Group 2 separating, after 24 hours of reperfusion. Transmission electron micrograph showing separation of the satellite cell (SC) from the skeletal myocyte (My). Note the basal lamina over the outer portion of the SC plasmalemma and over the entire surface of the myocyte sarcolemma (arrowheads). Also note the apparent in-growth of basal lamina between the SC and the My (arrows).

basal lamina and contained a large, irregularly shaped nucleus (Fig. 12). Mitochondria and other cytoplasmic organelles were similar to those described in the mobilising satellite cells of group 1.

Satellite cell and nuclear length and breadth, cell circularity (expressed as the ratio of breadth/length, with $1=$ a perfect circle), cross-sectional cell area, nuclear area and the ratio of nuclear to cell area expressed as a percentage for group 1 and group 2 are shown in Table I. The satellite cells in group 1 were significantly longer than the group 2 cells and this was associated with a significant reduction in the percentage of nuclear to cell area. The mean data for each of the 5 developmental phases of satellite cells is shown in Table II and the data are summarised in Fig. 13. Analysis of variance (ANOVA) with post hoc testing shows significant differences between quiescent cells and mobilised cells in group 1 for cell length $(p<0.001)$, circularity $(p<0.05)$, cell

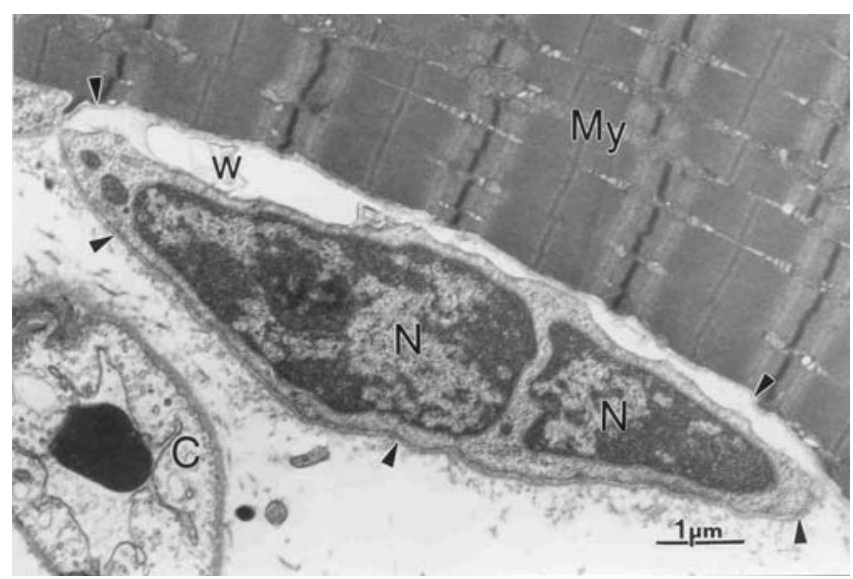

Fig. 9. Group 2 separating, after 24 hours of reperfusion. Transmission electron micrograph showing separation of the satellite cell (SC) from the myocyte (My). The basal lamina extends both over and between the two cells (arrowheads). Note bi-lobed nucleus and large membranous whorls (w).

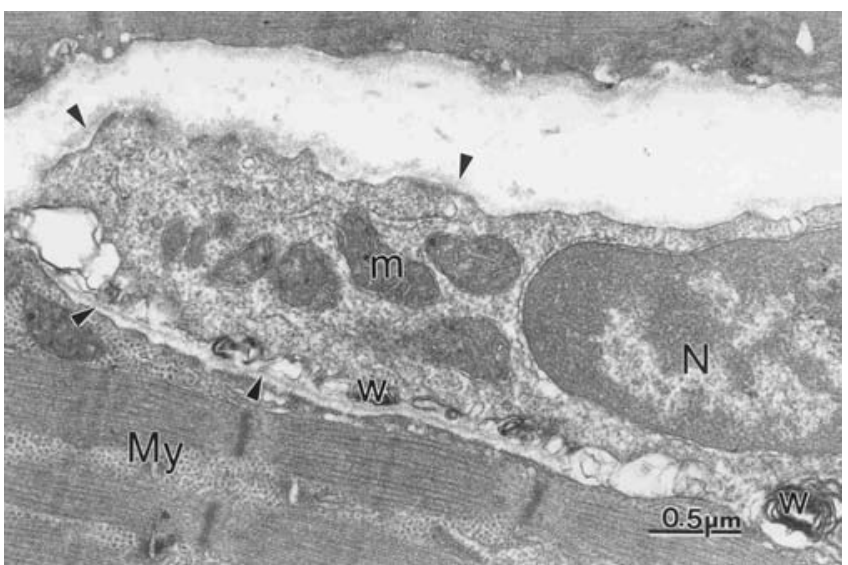

Fig. 10. Group 2 separating, after 24 hours of reperfusion. Transmission electron micrograph showing detail of basal lamina both over the satellite cell (SC) and in between the SC and the myocyte (My) (arrowheads). Note whorls of osmiophilic, membranous material between the cells (w).

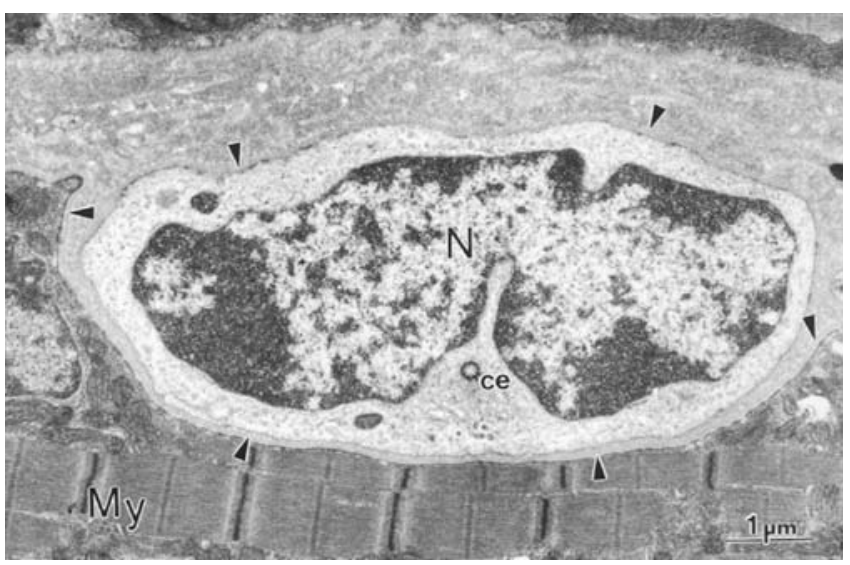

Fig. 11. Group 2 separating, after 12 hours of reperfusion. Transmission electron micrograph showing bi-lobed satellite cell (SC) encapsulated by basal lamina and separated from the myosite (My).

area $(p<0.05)$ and nuclear area $(p<0.05)$. Mobilised group 1 satellite cells were also significantly longer $(p<0.01)$, and had a smaller percentage of nuclear to cellular area $(p<0.01)$ than separating group 2 cells.

TABLE I. Cell length, width, circularity, area and nuclear area and the percentage of the nuclear to cell area (\%N/C area) are shown as means and one standard deviation

\begin{tabular}{llll}
\hline & Group 1 & Group 2 & t-test \\
\hline Number & 17 & 8 & $p$-value \\
Cell length $(\mu \mathrm{m})$ & $17.9+13.7$ & $8.9+2.2$ & 0.018 \\
Cell width $(\mu \mathrm{m})$ & $3.0+1.0$ & $3.3+0.8$ & 0.579 \\
Circularity & $0.3+0.2$ & $0.4+0.1$ & 0.106 \\
Cell area $\left(\mu \mathrm{m}^{2}\right)$ & $34.0+26.0$ & $23.8+10.3$ & 0.173 \\
Nuclear area $\left(\mu \mathrm{m}^{2}\right)$ & $17.4+11.2$ & $14.5+4.9$ & 0.364 \\
\%N/C area & $54.4+7.2$ & $62.9+6.8$ & 0.011 \\
& & & \\
& & &
\end{tabular}




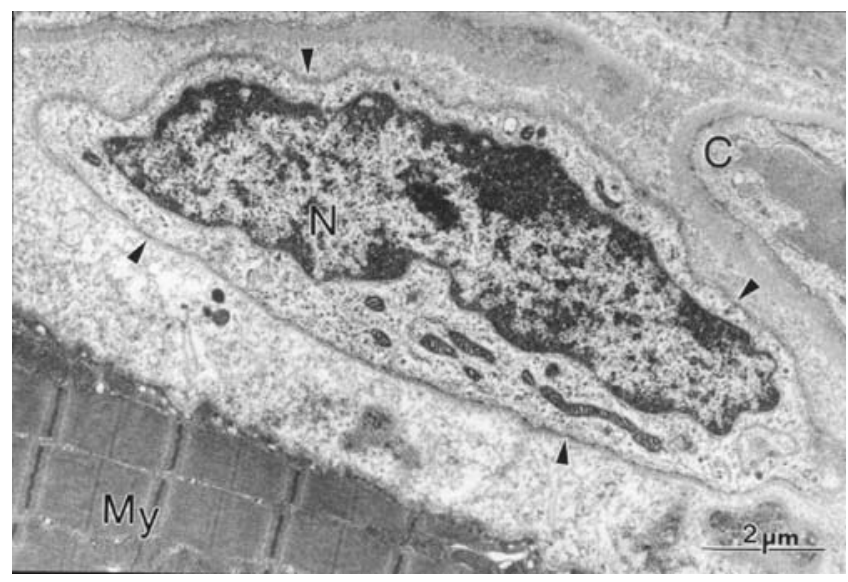

Fig. 12. Group 2 motile myoblast, after 36 hours of reperfusion. Transmission electron micrograph showing a myoblast in the intercellular space. Note that the cell is encapsulated by basal lamina (arrowheads).

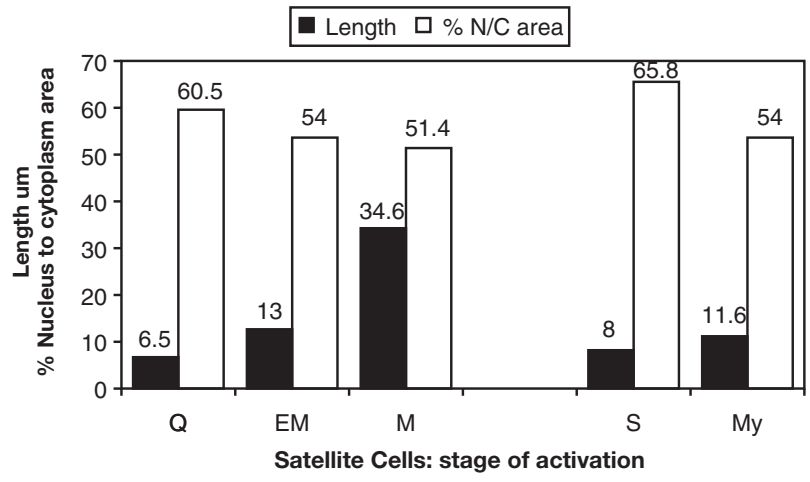

Fig. 13. Bar graph showing the average satellite cell length and the nuclear to cytoplasmic ratio expressed as a percentage, for satellite cells in each of the 5 stages of activation $(Q=$ quiescent, $E M=$ early mobilised, $M=$ mobilised, $S=$ separating and $M y=$ motile).

\section{Discussion}

To date there are no reports of the effect of an ischaemic reperfusion injury on satellite cell activity. The sequential morphological changes occurring in skeletal myofibres after periods of ischaemia and up to 24 hours reperfusion are, however, well described. ${ }^{17,18}$ In brief, a small number of irreversibly injured fibres exhibit progressive pathomorphological changes that result in cell death. In most cases, however, the ischaemic reperfusion injury is reversible, being expressed morphologically in the form of intermyofibrillar and juxta-nuclear oedema, swollen sarcoplasmic reticulum and t-tubes, damaged and/or necrotic mitochondria, focal areas of Z-band 'streaming', myofibrilysis and occasional internalised myonuclei.

In other models, using crushing, ${ }^{27}$ freezing, ${ }^{9}$ or chemically induced injuries to skeletal muscle ${ }^{12}$ to study satellite cell activation, proliferation and regeneration, two response of satellite cells to activation have been described. These are based on the integrity of the basal lamina. There is general consensus that following load-induced hypertrophy and/or a focal reversible injury, where the basal lamina has not been ruptured, myofibre repair is achieved by the chemotactic migration of activated satellite cells beneath the basal lamina to the site of injury. ${ }^{36,42}$ Satellite cell activation has been reported within 6 hours ${ }^{22}$ and mitosis is well underway within 24 hours of muscle overload or myotrauma. ${ }^{47}$ When in place, satellite cells are thought to fuse with the underlying myofibre, thereby participating in hypertrophic ${ }^{31}$ and repair processes. ${ }^{49}$ If the basal lamina is disrupted, satellite cells may move to adjacent myofibres by means of tissue bridges. ${ }^{40,48}$ While there is acceptance that satellite cells migrate to areas of need, changes in size, shape and ultrastructure during such migration are less well reported.

Satellite cell activation occurs in response to macrophagedependent cytokine stimuli. It is of interest that macrophages were not noted in either the light or EM specimens. Hormonal and growth factors are also known to influence muscle regeneration. ${ }^{2,20}$ Various in vitro studies have been used to investigate and demonstrate the effects of hormones ${ }^{10}$ and 'insulin-like' (IGF), ${ }^{21,29}$ hepatocyte (HGF), ${ }^{8}$ fibroblast (FGF ${ }^{44}$ and cytokine

\begin{tabular}{|c|c|c|c|c|c|c|c|}
\hline Stage & $N$ & $\begin{array}{l}\text { Cell } \\
\text { length }(\mu \mathrm{m})\end{array}$ & $\begin{array}{l}\text { Cell } \\
\text { width }(\mu \mathrm{m})\end{array}$ & Circularity & $\begin{array}{l}\text { Cell } \\
\text { area }\left(\mu \mathrm{m}^{2}\right)\end{array}$ & $\begin{array}{l}\text { Nuclear } \\
\text { area }\left(\mu \mathrm{m}^{2}\right)\end{array}$ & $\begin{array}{c}\% \mathrm{~N} / \mathrm{C} \\
\text { area }\end{array}$ \\
\hline \multicolumn{8}{|l|}{ Group 1} \\
\hline Quiescent & 4 & $6.5+1.1^{\ddagger}$ & $2.9+0.9$ & $0.47+0.18^{*}$ & $14.4+5.2^{*}$ & $8.6+2.8^{*}$ & $60.5+5.2$ \\
\hline Range & & $5.7-8.0$ & $1.7-3.8$ & $0.21-0.60$ & $7.4-19.8$ & $5.0-11.6$ & $56-68$ \\
\hline Early mobilised & 6 & $12.1+1.5$ & $3.4+1.2$ & $0.29+0.12$ & $27.1+11.1$ & $14.8+5.4$ & $55.3+6.2$ \\
\hline Range & & $10.2-14.3$ & $1.9-4.9$ & $0.13-0.43$ & $18.4-46$ & $8.9-22.5$ & $48-64$ \\
\hline Mobilised & 7 & $29.4+15^{\ddagger \ddagger}$ & $2.8+0.9$ & $0.11+0.06^{*}$ & $51.3+32.1^{*}$ & $24.8+13.4^{*}$ & $50.1+6.8^{\dagger}$ \\
\hline Range & & $15.0-60.0$ & $1.6-3.9$ & $0.06-0.21$ & $24.9-105$ & $11.7-43.5$ & $41-60$ \\
\hline \multicolumn{8}{|l|}{ Group 2} \\
\hline Separating & 6 & $8.0+1.7^{\dagger}$ & $2.9+0.6$ & $0.38+0.14^{*}$ & $19.3+6.7$ & $12.6+4.1$ & $65.8+3.5^{\dagger}$ \\
\hline Range & & $7.0-9.5$ & $2.3-3.9$ & $0.26-0.63$ & $11.2-29.4$ & $7.0-18$ & $61-71$ \\
\hline Motile & 2 & $11.6+0.2$ & $4.3+0.8$ & $0.37+0.06$ & $37.4+5.4$ & $20.0+0.3$ & $54.0+7.1$ \\
\hline Range & & $11.4-11.7$ & $3.7-4.8$ & $0.32-0.41$ & $33.6-41.2$ & $19.8-20.2$ & $49-59$ \\
\hline ANOVA ( $p$-value) & & 0.0002 & 0.4380 & 0.0044 & 0.0053 & 0.3638 & 0.0105 \\
\hline
\end{tabular}


'transforming' (TGF) ${ }^{37}$ growth factors on satellite cell proliferation and differentiation.

In this study, we employed 3 hours of tourniquet-mediated ischaemia, and the subsequent additional injury caused by reperfusion, to follow the phases of satellite cell activation and mobilisation in vervet monkey skeletal muscle. The study is primarily concerned with graphically detailing the sequential changes that satellite cells undergo following muscle injury. We are aware that multiple muscle biopsy, per se, will almost certainly activate satellite cells. Our results, therefore, may not exclusively represent the effect that the largely reversible ischaemic reperfusion injury has on both muscle and satellite cells but may include an additional irreversible injury caused by the mechanical trauma of multiple biopsy of adjacent muscle fibres.

Based on the different morphological and morphometric appearances of the satellite cells over time we have grouped the cells into those that appear to be migrating under the basal lamina and those that appear to be separating and migrating to adjacent myofibres. Typically, quiescent satellite cells in mammalian skeletal muscle are reported to average $25 \mu \mathrm{m}$ in length, $4 \mu \mathrm{m}$ in height and $5 \mu \mathrm{m}$ in width. ${ }^{1}$ With the exception of increased numbers near myoneural junctions and capillaries, ${ }^{26}$ they are thought to be evenly distributed along the length of the myofibre. Satellite cells associated with tension-free myofibres are reported to be orientated obliquely to the long axis of the fibre. ${ }^{1}$ In this study, as all specimens were orientated to facilitate longitudinal sectioning, most satellite cells were probably transversely/obliquely sectioned. This appears to be the case, for most quiescent satellite cells did not exceed $4.5 \mu \mathrm{m}$ in height and were not shorter than $5.2 \mu \mathrm{m}$ in cross-sectional width.

From 6 to 12 hours after reperfusion, some group 1 satellite cells were noted to have elongated. Within 24 hours, their circularity had changed from 0.47 to 0.29 and average cell length had increased from $6.5 \mu \mathrm{m}$ to $12.1 \mu \mathrm{m}$. Whether such change in shape was a consequence of satellite cell elongation or reorientation of the satellite cells with regard the longitudinal axis of the myofibre, could not be determined from the two-dimensional images. However, 48 hours after reperfusion, circularity was reduced to 0.11 , some cells were $60 \mu \mathrm{m}$ in length and the average cross-sectional area of satellite cells had increased by $356 \%$. Taken sequentially these data appear to confirm the elongation of activated satellite cells for 48 hours after reperfusion, with activated satellite cells being orders of magnitude longer/larger than quiescent cells. They do, however, throw into question whether satellite cells do indeed migrate or simply expand through the inter-basal lamina/sarcolemmal space, over the fibre surface - rather like the white of an egg spreads when an egg is broken into a pan.

Irrespective of whether satellite cells migrate and/or expand over the fibre surface, from 36 hours after reperfusion, in some samples the opposing satellite cell plasmalemma and sarcolemma of the host fibre appeared to be incomplete. Such fragmentation would enable the contents of the satellite cells to mix with the sarcosol of its host myofibre. The progressive changes in the morphological appearance of satellite cells comprising group 1, suggest that quiescent, early mobilised and mobilised satellite cells may be sequential phases in the remodelling of satellite cells in response to reversible myofibre injury.

Present theory suggests that following a more serious injury, where the basal lamina has been broken and myofibres may die, satellite cells associated with both healthy and injured myofibres proliferate and migrate to damaged areas. ${ }^{48}$ Once in position, these satellite cells/presumptive myoblasts will either fuse with damaged myofibres to attempt repair, or fuse together to form a myotube, thereby replacing irreversibly injured and necrotic myofibre. ${ }^{5,822,45}$ The satellite cells that we have classified as group 2, or 'separating' satellite cells, are similar in many respects to quiescent cells in group 1 . They are however characterised by the features of the breakdown of the satellite cell membrane and the sarcolemma interface with the apparent 'in-growth' and development of basal lamina between the satellite cell plasmalemma and sarcolemma of the host myofibre. In all cases, these cells, although contained within the basal lamina, appeared to be separating from their host myofibre. All separating satellite cells were found to be associated with apparently normal myofibres within 24 hours of reperfusion and their size and shape were similar to intercellular myoblasts. Group 2 satellite cells could be a different subset of satellite cells whose role is migratory and whose purpose is the eventual genesis of new myofibres or repair at distant sites.

There is considerable evidence to suggest that although quiescent satellite cells in different muscle types are morphologically similar, they may not represent a homogeneous cell line with unequivocally predictable, differentiative outcomes. It is well known that the size of satellite cell populations varies with type of muscle, with oxidative myofibres having larger numbers of satellite cells than glycolytic fibres. ${ }^{3,13}$ Further, in culture medium, satellite cells from slow-twitch muscles have been shown to differentiate more quickly and fuse into more numerous myotubes than those from fast-twitch muscle. ${ }^{4}$ In addition, it has been suggested that a distinction may exist between satellite cells mobilised to effect repair and regeneration and those destined to maintain the progenitor pool of satellite cells for subsequent rounds of hypertrophy or regeneration. ${ }^{8}$ The disparate morphology of group 1 and 2 satellite cells in this study gives credence to a postulate that in addition to the above, satellite cells may also be divided into functional types whose activation and eventual differentiation is dependent on the nature and severity of muscle injury.

Most authors report that following activation, satellite cells proliferate - we found no direct evidence of mitosis. The separating satellite cells of group 2 did show features suggestive of mitotic activity. Their nuclei tended to be multi-lobed, with condensed chromatin, a particularly high nucleus to cytoplasmic area ratio and in some instances, contained a well-defined centriole, all features suggestive of mitotic activity. As we did not observe more than one satellite cell at any site and as most separating satellite cells were observed within 12 hours of reperfusion, the cells are more likely to be preparing for division than to have already divided. These features may represent various degrees of cell division between prophase and anaphase and that following activation, satellite cells destined to divide become encapsulated with basal lamina prior to and perhaps during the process of division.

In conclusion, this study describes the appearance of satellite cells in vervet monkey muscle at different times after ischaemic reperfusion muscle injury. Two patterns of response are described. Satellite cell function and anomalies, morphological, cytochemical and genetic, are the focus of research into reasons why dystrophic muscle continues to degenerate, 
why muscle hypertrophies and the effects of ageing on muscle. It is hoped that by characterising the variable appearance of satellite cells in normal muscle, the data can be used to identify pathomorphological anomalies in dystrophic muscle, hypertrophied muscle and ageing muscle thereby contributing to a better understanding of why and how these processes occur.

\section{REFERENCES}

1. Allbrook D. Skeletal muscle regeneration. Muscle Nerve 1981; 4: 234-45.

2. Allen RE, Boxhorn LK. Regulation of skeletal muscle satellite cell proliferation and differentiation by transforming growth factor-beta, insulin-like growth factor I, and fibroblast growth factor. J Cell Physiol 1989; 138: 311-5.

3. Barjot C, Cotten ML, Goblet C, Whalen RG, Bacou F. Expression of myosin heavy chain and of myogenic regulatory factor genes in fast or slow rabbit muscle satellite cell cultures. J Muscle Res Cell Motil 1995; 16: 619-28.

4. Barjot C, Rouanet P, Vigneron P, Janmot C, d'Albis A, Bacou F. Transformation of slow- or fast-twitch rabbit muscles after cross-reinnervation or low frequency stimulation does not alter the in vitro properties of their satellite cells. J Muscle Res Cell Motil 1998; 19: 25-32.

5. Bischoff R. The satellite cell and muscle regeneration. In: Engel AG, Franzini-Armstrong C, eds. Myology. New York: McGraw-Hill, 1994: 97118.

6. Bittner RE, Schofer C, Weipoltshammer K, et al. Recruitment of bone-marrow-derived cells by skeletal and cardiac muscle in adult dystrophic $\mathrm{mdx}$ mice. Anat Embryol 1999; 199: 391-6.

7. Brown SC, Stickland NC. Satellite cell content in muscles of small and large mice. J Anat 1993; 183: 91-6.

8. Cornelison DD, Wold BJ. Single-cell analysis of regulatory gene expression in quiescent and activated mouse skeletal muscle satellite cells. Dev Biol 1997; 191: 270-83.

9. Creuzet S, Lescaudron L, Li Z, Fontaine-Perus J. MyoD, myogenin, and desmin-nls-lacZ transgene emphasize the distinct patterns of satellite cell activation in growth and regeneration. Exp Cell Res 1998; 243: 241-53.

10. Dodson MV, McFarland DC, Grant AL, Doumit ME, Velleman SG. Extrinsic regulation of domestic animal-derived satellite cells. Domest Anim Endocrinol 1996; 13: 107-26.

11. Ferrari G, Cusella-De Angelis G, Coletta M, et al. Muscle regeneration by bone marrow-derived myogenic progenitors. Science 1998; 279: 1528-30.

12. Garry DJ, Meeson A, Elterman J, et al. Myogenic stem cell function is impaired in mice lacking the forkhead/winged helix protein MNF. Proc Natl Acad Sci USA 2000; 97: 5416-21.

13. Gibson MC, Schultz E. The distribution of satellite cells and their relationship to specific fiber types in soleus and extensor digitorum longus muscles. Anat Rec 1982; 202: 329-37.

14. Gibson MC, Schultz E. Age-related differences in absolute numbers of skeletal muscle satellite cells. Muscle Nerve 1983; 6: 574-80.

15 Goodell MA, Brose K, Paradis G, Conner AS, Mulligan RC. Isolation and functional properties of murine hematopoietic stem cells that are replicating in vivo. J Exp Med 1996; 183: 1797-806.

16. Goodell MA, Jackson KA, Majka SM, et al. Stem cell plasticity in muscle and bone marrow. Ann N Y Acad Sci 2001; 938: 208-18.

17. Gregory MA, Mars M. Alterations in the morphology of skeletal myofibers after 90 minutes of ischaemia and 3 hours of reperfusion. $S$ Afr Med $J$ 1991; 79: 307-11.

18. Gregory MA, Mars M. Serial morphological changes in primate skeletal myofibers after 3 hours of ischaemia and 24 hours of reperfusion. $S$ Afr Med J 1992; 81: 473-8.

19. Grounds MD. Towards understanding skeletal muscle regeneration. Pathol Res Pract 1991; 187: 1-22.

20. Grounds MD. Muscle regeneration: Molecular aspects and therapeutic implications. Curr Opin Neurol 1999; 12: 535-43.

21. Halevy $O$, Hodik V, Mett $A$. The effects of growth hormone on avian skeletal muscle satellite cell proliferation and differentiation. Gen Comp Endocrinol 1996; 101: 43-52.

22. Hawke TJ, Garry DJ. Myogenic satellite cells: physiology to molecular biology. J Appl Physiol 2001; 91: 534-51.

23. Jackson KA, Mi T, Goodell MA. Hematopoietic potential of stem cells isolated from murine skeletal muscle. Proc Natl Acad Sci USA 1999; 96: 14482-6.

24. Karnovsky MJ. A formaldehyde glutaraldehyde fixative of high osmolarity for use in electron microscopy. J Cell Biol 1965; 26: 31-4.

25. Karpati G, Pouilot Y, Zubrzycka-Gaarn EE, et al. Dystrophin is expressed in $\mathrm{mdx}$ skeletal muscle fibers after normal myoblast implantation. $A m \mathrm{~J}$
Pathol 1989; 135: 27-32.

26. Kelly AM. Perisynaptic satellite cells in the developing and mature rat soleus muscle. Anat Rec 1978; 190: 891-903.

27. Kurek JB, Bower JJ, Romaella M, Koentgen F, Murphy M, Austen L. The role of leukemia inhibiting factor in skeletal muscle regeneration. Muscle Nerve 1997; 20: 815-22.

28. Law PK, Goodwin TG, Wang MG. Normal myoblast injections provide genetic treatment for murine dystrophy. Muscle Nerve 1988; 11: 525-33.

29. LeRoith D, McGuiness M, Shemer J, et al. Insulin-like growth factors. Biol Signals 1992; 1: 173-81.

30. Mauro A. Satellite cell of skeletal muscle fibers. J Biophys Biochem Cytol 1961; 9: 493-8.

31. McCormick KM, Schultz E. Role of satellite cells in altering myosin expression during avian skeletal muscle hypertrophy. Dev Dyn 1994; 199: 52-63.

32. Muir AR, Kanji AH, Allbrook D. The structure of the satellite cells in skeletal muscle. J Anat 1965; 99: 435-44.

33. Olmesdahl PJ, Gregory MJ, Cameron EWJ. Ultrastructural artefacts in biopsied normal myocardium and their relevance to myocardial biopsy in man. Thorax 1979; 34: 82-90.

34. Ordahl CP, Williams BA, Denetclaw W. Determination and morphogenesis in myogenic progenitor cells: an experimental embryological approach. Curr Top Dev Biol 2000; 48: 319-67.

35. Reynolds ES. The use of lead citrate at high $\mathrm{pH}$ as an electron opaque stain in electron microscopy. J Cell Biol 1962; 17: 208-12.

36. Rosenblatt JD, Yong D, Parry DJ. Satellite cell activity is required for hypertrophy of overloaded adult rat muscle. Muscle Nerve 1994; 17: 608-13.

37. Sakuma K, Watanabe K, Sano M, et al. The adaptive response of transforming growth factor-2 and -RII in the overloaded and regenerating and denervated muscle of rats. Acta Neuropathol 2000; 99: 177-85.

38. Schmalbruch $\mathrm{H}$, Hellhammer $\mathrm{U}$. The number of nuclei in adult rat muscles with special reference to satellite cells. Anat Rec 1977; 189: 169-75.

39. Schultz E. Satellite cell behavior during skeletal muscle growth and regeneration. Med Sci Sport Exerc 1989; 21: S181-6.

40. Schultz E, Jaryszak DL, Gibson MC, Albright DJ. Absence of exogenous satellite cell contribution to regeneration of frozen skeletal muscle. $J$ Muscle Res Cell Motil 1986; 7: 361-7.

41. Schultz E, Jaryszak DL, Valliere CR. Response of satellite cells to focal skeletal muscle injury. Muscle Nerve 1985; 8: 217-22.

42. Schultz E, McCormick KM. Skeletal muscle satellite cells. Rev Physiol Biochem Pharmacol 1994; 123: 213-57.

43. Seale P, Rudnicki MA. A new look at the origin, function, and "stem-cell" status of muscle satellite cells. Dev Biol 2000; 218: 115-24.

44. Sheehan SM, Allen RE. Skeletal muscle satellite cell proliferation in response to members of the fibroblast growth factor family and hepatocyte growth factor. J Cell Physiol 1999; 181: 499-506.

45. Snow MH. Myogenic cell formation in regenerating rat skeletal muscle injured by mincing. I. A fine structural study. Anat Rec 1977; 188: 181-99.

46. Spurr AR. A low viscosity embedding medium for electron microscopy. $J$ Ultrastruct Res 1969; 26: 31-4.

47. Thorsson O, Rantanen J, Hurme T, Kalimo H. Effects of nonsteroidal antiinflammatory medication on satellite cell proliferation during muscle regeneration. Am J Sports Med 1998; 26: 172-6.

48. Watt DJ, Morgan JE, Clifford MA, Partridge TA. The movement of muscle precursor cells between adjacent regenerating muscles in the mouse. Anat Embryol 1987; 175: 527-36.

49. Winchester PK, Gonyea WJ. Regional injury and the terminal differentiation of satellite cells in stretched avian slow tonic muscle. Dev Biol 1992; 151: 459-72.

50. Wokke JH, Van den Oord CJ, Leppink GJ, Jennekens FG. Perisynaptic satellite cells in human external intercostal muscle: a quantitative and qualitative study. Anat Rec 1989; 223: 174-80. 